\title{
Effects of the menstrual cycle on vibrotactile sensitivity
}

\author{
GEORGE A. GESCHEIDER \\ Hamilton College, Clinton, New York \\ RONALD T. VERRILLO \\ Institute for Sensory Research, Syracuse University, Syracuse, New York \\ and \\ JOSEPH T. McCANN and ERIC M. ALDRICH \\ Hamilton College, Clinton, New York
}

\begin{abstract}
Psychophysical thresholds for the detection of vibration delivered to the thenar eminence of the right hands of young males and females were measured every other day for 30-34 days. The frequency of the vibratory stimulus was either 15 or $250 \mathrm{~Hz}$. The sinusoidal stimuli applied through a $3.0-\mathrm{cm}^{2}$ contactor were $700 \mathrm{msec}$ in duration and had rise-fall times of $25 \mathrm{msec}$. Stimulus amplitude was measured with a calibrated accelerometer mounted on the moving element of the vibrator. Data were plotted as a function of successive days in the menstrual cycle. Thresholds for detecting the $15-\mathrm{Hz}$ stimulus did not change significantly, whereas thresholds for detecting the $250-\mathrm{Hz}$ stimulus varied significantly over the menstrual cycle. The $250-\mathrm{Hz}$ threshold became progressively lower as subjects approached the onset of menstruation. After the onset of menstruation, the $250-\mathrm{Hz}$ threshold gradually increased, reaching a maximum value approximately 12 or 13 days later. Soon after the 12th or 13th day of the cycle, the threshold again began to decline and continued to decline until the onset of the next menstrual cycle. The thresholds of women taking birth control pills did not change systematically over the testing period.
\end{abstract}

The sensitivity of human sensory systems has been found to be related to the menstrual cycle (see Parlee, 1983, for a review). Visual thresholds tend to be lowest at the time of ovulation (e.g., Barris, Dawson, Theiss, 1980, and Scher, Pionk, \& Purcell, 1981). Olfactory thresholds also tend to be lower at midcycle than during menstruation (e.g., Mair, Bouffard, Engen, \& Morton, 1978). On the other hand, taste thresholds tend to be lowest during menstruation (Henkin, 1974). Auditory sensitivity increases during ovulation and decreases just prior to menstruation (Henkin, 1974).

Cutaneous sensitivity is also affected by the menstrual cycle. Sensitivity to painful radiant heat on the forearm is highest during ovulation (Goolkasian, 1980). On the other hand, pricking pain thresholds on the breast are lowest at midcycle and at menstruation (Robinson \& Short, 1977). Kenshalo (1966) showed that the detection of changes in skin temperature is related to the menstrual cycle. When the skin has been adapted to temperature greater than $35^{\circ} \mathrm{C}$, the threshold for detecting a cooling of the skin is higher during the period from the onset of

This research was supported in part by Grant NS-09940 from the National Institutes of Health, United States Department of Health and Human Services.

The senior author's mailing address is: Department of Psychology, Hamilton College, Clinton, NY 13323. menstruation to ovulation than after ovulation. Lower thresholds after ovulation were attributed to increased cutaneous vasodilation associated with increased levels of progesterone. Two-point tactile discrimination thresholds change as a function of the menstrual cycle. Herren (1933) and Henkin (1974) found tactile spatial acuity on the skin as measured by two-point thresholds to be better in the period after ovulation and before menstruation than in the period before and during ovulation. Millidot and Lamont (1974) found that touch sensitivity of the cornea was lowest just before and at the start of menstruation. In contrast to this finding, Robinson and Short (1977) found twopoint sensitivity of the breast to be high just prior to and during menstruation as well as at midcycle. The peak in sensitivity at midcycle was absent in women taking birth control pills, but, as with the normally cycling women, their breasts were highly sensitive just prior to and during menstruation.

The purpose of the present study was to investigate the effects of the menstrual cycle on vibrotactile sensitivity. Psychophysical thresholds for the detection of low- and high-frequency vibration at the thenar eminence of the hand were measured at various times in the menstrual cycle. Some subjects took birth control pills and some did not. Male subjects were also tested. The results confirmed the hypothesis that the menstrual cycle affects vibrotactile sensitivity. 


\section{EXPERIMENT 1}

The purpose of Experiment 1 was to determine whether, over the course of the menstrual cycle, there was a change in the threshold for detecting vibration. Thresholds were measured for the detection of both lowand high-frequency vibration applied to the thenar eminence of the hand.

Recent studies on the enhancement of the subjective magnitude of one vibrotactile stimulus by another (Gescheider \& Verrillo, 1982; Gescheider, Verrillo, Capraro, \& Hamer, 1977; Verrillo \& Gescheider, 1975), selective adaptation (Gescheider, Frisina, \& Verrillo, 1979; Verrillo \& Gescheider, 1977), and masking (Gescheider, O'Malley, \& Verrillo, 1983; Gescheider, Verrillo, \& Van Doren, 1982; Hamer, Verrillo, \& Zwislocki, 1983; Labs, Gescheider, Fay, \& Lyons, 1978; Verrillo, Gescheider, Calman, \& Van Doren, 1983) support the hypothesis that there are at least two independent information processing channels for detecting vibration on the skin. Two classes of mechanoreceptors, Pacinian corpuscles and non-Pacinian receptors, have been identified as the input stages to each of these channels. Through both psychophysical techniques (Gescheider, 1976; Verrillo, 1963, 1966a, 1966b, 1968; Verrillo \& Gescheider, 1977) and neurophysiological techniques (Bolanowski \& Verrillo, 1982; Mountcastle, LaMotte, \& Carli, 1972; Talbot, Darian-Smith, Kornhuber, \& Mountcastle, 1968), the frequency response of the Pacinian system has been found to be U-shaped with a maximum sensitivity between 200 and $400 \mathrm{~Hz}$. The non-Pacinian system, on the other hand, has a relatively flat frequency response between 10 and $700 \mathrm{~Hz}$ according to psychophysical experiments (e.g., Gescheider, 1976; Verrillo, 1963, 1968). The threshold of the non-Pacinian system is much lower than that of the Pacinian system at low frequencies and much higher at high frequencies. This difference in sentivities provides a means for experimentally isolating the two receptor systems. Thus, to investigate the effect of the menstural cycle on the sensitivity of both vibrotactile systems, subjects were tested throughout their cycle at test-stimulus frequencies of $15 \mathrm{~Hz}$ to assess the sensitivity of the nonPacinian system and $250 \mathrm{~Hz}$ to assess the sensitivity of the Pacinian system.

\section{Method}

Subjects. Eleven women, ranging in age from 18 to 26 years, served as paid subjects. All but one subject were undergraduate students. All students had normal menstrual cycles with durations of $28 \pm 2$ days. During the experiment, the subjects did not use drugs for either medicinal or recreational purposes. They also maintained normal patterns of sleep and food and water intake. Before the experiment, all subjects were trained in detecting vibrotactile stimuli.

Apparatus. Sinusoidal vibration, with 700-msec duration and risefall times of $25 \mathrm{msec}$, was delivered to the thenar eminence of the subject's right hand. The $3.0-\mathrm{cm}^{2}$ contactor of the vibrator was adjusted so that it made a depression of $0.5 \mathrm{~mm}$ into the surface of the skin. The circular contactor protruded through a hole in the surface of the table upon with the subject rested her hand. The gap between the contactor and the surround was $1.0 \mathrm{~mm}$. The use of this rigid surround restricted the vibration to the immediate vicinity of the contactor. Vibration amplitude was measured with a calibrated accelerometer mounted on the moving element of the vibrator. Accelerometer voltage readings were transformed to peak displacement of the contactor into the skin. All measurements were made during stimulation of the skin while the subject's hand was in the test position. Thus, measurement of contactor movement at threshold yielded a measurement of the amplitude of skin movement at threshold.

The subject and vibrator assembly were located in a soundproofed booth to provide isolation from vibrations of the building and sounds in the laboratory. The vibrator assembly was positioned on an adjusted platen which could be precisely raised or lowered to regulate the position of the contactor relative to the skin of the subject's hand as it rested on the table above the vibrator. Also, the $3.0-\mathrm{cm}^{2}$ contactor was shaped to contour the surface of the skin when the hand was in position over the hole in the rigid surround.

Procedure. Vibrotactile thresholds were measured using a twointerval forced-choice tracking method (Zwislocki, Maire, Feldman, \& Rubin, 1958). Two observation intervals, each marked by a separate light, were presented to the subject, one containing the test stimulus and the other not. By pressing the appropriate button, the subject indicated in which interval the test stimulus occurred. Only after a response by the subject were the observation intervals presented again. The occurrence of the test stimulus was distributed randomly between the two intervals with a probability of 0.5 of the test stimulus occurring in each interval. The intensity of the signal was controlled by a computer so that the stimulus amplitude was attenuated $1.0 \mathrm{~dB}$ following three correct responses (consecutive or not) and increased $1.0 \mathrm{~dB}$ in amplitude following one incorrect response. Thus, threshold was defined as the amplitude of a stimulus that could correctly be detected $75 \%$ of the time. Within each trial, the threshold was measured at the end of a 2.0-3.0-min period in which the variation in the subject's tracking around an average value was $2.0 \mathrm{~dB}$ or less. Threshold was the average intensity recorded during this 2.0 -min period.

The subjects were tested at the same time every other day in the late afternoon. Each testing session lasted approximately $15 \mathrm{~min}$. Testing of each subject was conducted over a period lasting between 1 and $1 \frac{1}{2}$ months. The experiment was conducted at three different times, at which slightly different procedures were used. Four of the subjects were tested during the months of February and March of 1983 and four were tested during the same months of 1984 . Finally, three subjects were tested during April and May of 1984. In the first and second replications of the experiment, the body weight of each subject was measured at each testing session. During the second replication, skin temperature of the hand at the test site was monitored during the testing session.

\section{Results and Discussion}

In Figure 1, the mean thresholds of the 11 subjects are plotted as a function of successive days in the menstrual cycle. Day 1 in the cycle was defined as the day the subject's menstrual flow started or, if testing did not occur on that day, as the day after the menstrual flow started. The bars above and below each data point indicate the standard error of the mean. Two single-factor analyses of variance were used to test for the effects of days in the menstrual cycle. Thresholds for the detection of the $15-\mathrm{Hz}$ stimulus did not change significantly over the menstrual cycle $[F(13,130)=.75, p>.05]$. Thresholds for detecting the $250-\mathrm{Hz}$ stimulus, on the other hand, varied significantly over the menstrual cycle $[F(13,130)=3.27$, 


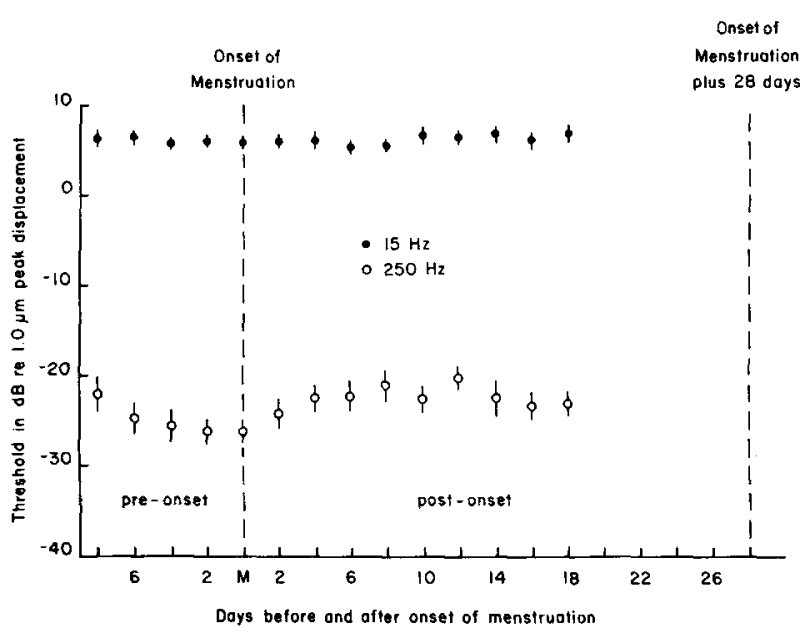

Figure 1. Absolute thresholds for the detection of 15- and 250-Hz vibrotactile stimuli as a function of days in the menstrual cycle. Average of 11 subjects.

$\mathrm{p}<.01]$. The $250-\mathrm{Hz}$ threshold became progressively lower as subjects approached the onset of menstruation. After the onset of menstruation the threshold gradually increased, reaching a maximum value approximately 12 or 13 days later. Soon after the 12 th or 13 th day of the cycle, the threshold again began to decrease. For the four subjects who were tested long enough, this decrease was found to continue until the onset of the next menstrual period. These results are shown in Figure 2.

Sensitivity levels of different subjects varied considerably, and this variability was greater for the detection of $250-\mathrm{Hz}$ than of $15-\mathrm{Hz}$ test stimuli. All but one subject was more sensitive to the $250-\mathrm{Hz}$ stimulus during the week before the onset of menstruation than during the week after the cessation of menstruation. The magnitude of the change in sensitivity from the premenstrual to the postmenstrual phase of the cycle varied considerably among subjects. The difference between the premenstrual

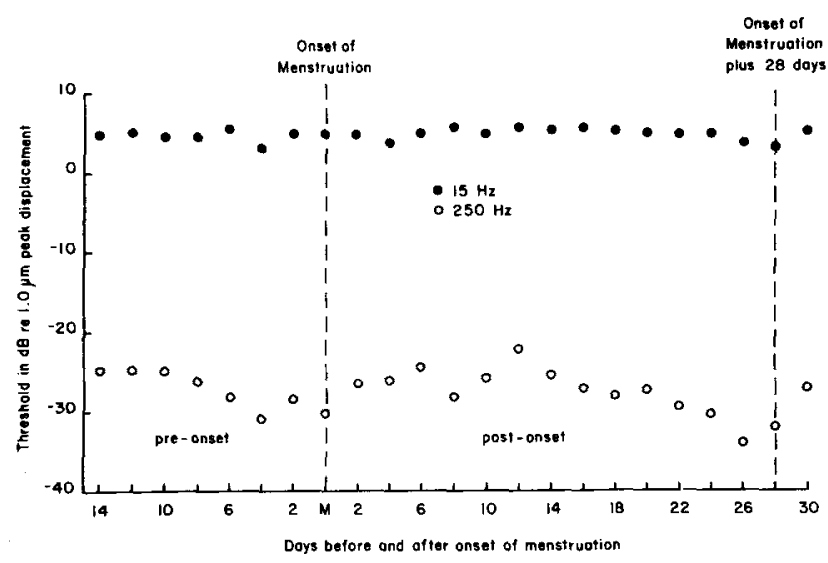

Figure 2. Absolute thresholds for the detection of $15-$ and $250-\mathrm{Hz}$ vibrotactile stimuli as a function of days in the menstrual cycle. Average of four subjects. thresholds (average of Day $M$ and 4 and 2 days before the period) and postmenstrual thresholds (average of Days 10,12 , and 14 after the onset of the period) was as small as $-.8 \mathrm{~dB}$ and as large as $8.0 \mathrm{~dB}$. Of the remaining nine subjects, three showed a relatively small change of approximately $2.0 \mathrm{~dB}$, whereas the other six exhibited substantial changes of 5.0 to $7.0 \mathrm{~dB}$. The magnitude of this menstrual-cycle effect did not appear to be related to the average sensitivity of the subject, or body weight, or weight change from premenstrual to postmenstrual phases.

The average weight, skin temperature, and $250-\mathrm{Hz}$ thresholds of the seven subjects upon whom we maintained these measurements are shown in Figure 3. Weight changed very little over the menstrual cycle. In fact, for individual subjects, the difference in body weight between the premenstrual and postmenstrual phase of the cycle was at most $1.5 \mathrm{lb}$. It is often assumed that transient increases in body weight during the premenstrual phase are due to water retention. Since weight did not fluctuate in our subjects, body-weight measurements failed to support the hypothesis that changes in sensitivity to high-frequency vibration were due to changes in water retention. The water- retention hypothesis, although not supported, seemed worthy of investigation, since the receptor known to mediate the detection of high-frequency vibration, the Pacinian corpuscle, is largely made up of fluid. Specifically, the Pacinian corpuscle consists of a nerve fiber surrounded by many layers of tissue separated by fluid. It was thought that increases in water retention during the premenstrual phase might increase the amount of fluid in the capsule surrounding the nerve fiber and, consequently, change the effectiveness by the which the capsule conducts the mechanical stimulus to the nerve fiber. Because we did not measure changes in fluid volume in sensory receptors, it remains a possibility that increased sensitivity to high-frequency vibration during the premenstrual phase may have resulted from increased water retention by Pacinian corpuscles not reflected in body-weight changes.

Another hypothesis that may account for premenstrual increases in sensitivity to high-frequency vibration is that psychophysical thresholds change during the menstrual cycle because skin temperature changes. Bolanowski and Verrillo (1982) varied the temperature of the bathing solution of Pacinian corpuscles taken from cats and the skin temperature of the hands of their human subjects and found that changes in temperature had a strikingly similar effect on psychophysical and neural thresholds. In both cases, thresholds decreased as temperature increased, at a rate that would require a natural variation in temperature between approximately $22^{\circ}$ and $30^{\circ} \mathrm{C}$ to account for the 6.0- $\mathrm{dB}$ change in threshold seen in Figure 3. Figure 3 shows that, in our experiment, skin temperature did not vary this much, but was, in fact, a nearly constant $30^{\circ} \mathrm{C}$ throughout the menstrual cycle. The slight drop in skin temperature to $28^{\circ} \mathrm{C}$ on the 12 th day after the onset of the menstrual period is associated with an increase in the psychophysical threshold of about $1.5 \mathrm{~dB}$. The skin tem- 


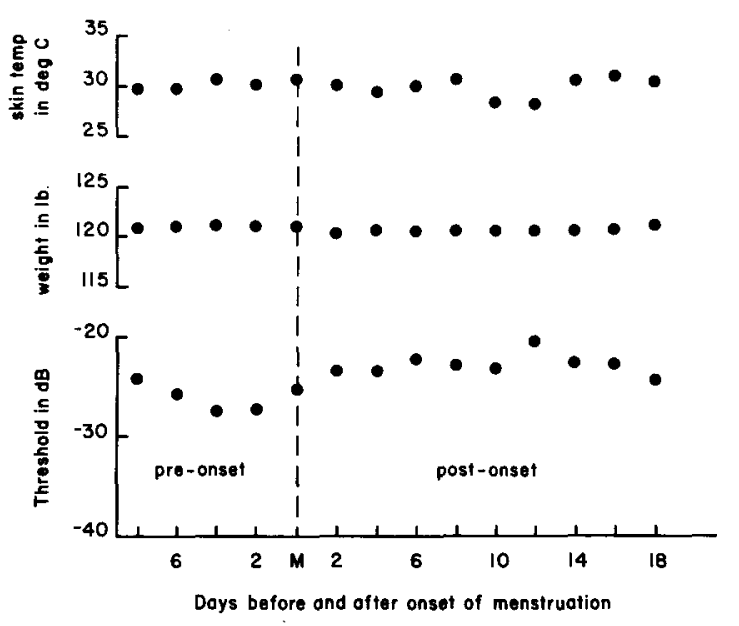

Figure 3. Absolute thresholds for the detection of a $250-\mathrm{Hz}$ vibrotactile stimulus, and body weight (average data of seven subjects) and skin temperature (average data of four subjects) as a function of days in the menstrual cycle.

perature was also $28^{\circ} \mathrm{C}$ on Day 10 , however, and no elevation of threshold was observed. Thus, naturally occurring skin temperature change does not appear to be a promising candidate for an explanation of why psychophysical thresholds for the detection of high-frequency vibration change during the menstrual cycle.

This experiment demonstrated that the menstrual cycle affects psychophysical thresholds mediated by Pacinian corpuscles, but failed to detect any peripheral physiological changes that could account for the phenomenon. The menstrual cycle may affect the subject's performance in a threshold-measurement task through changes in cognition, such as decision strategy and attention, and/or changes in motivation, such as general arousal level. Such cognitive and motivational explanations, however, can be ruled out for two reasons. First, the two-interval forcedchoice tracking procedure used in our experiment provides threshold measurements that are insensitive to changes in the subject's criterion. The assumption is made that, in the absence of response bias toward one of the observation intervals, the subject chooses the observation interval containing the larger sensory event. Since the subject's criterion is not a factor in such a judgment, the proportion of correct responses is used as a measure of sensitivity. (See, e..g., Gescheider, 1985, for a more extended description of the logic of the 2I-FC method.) Our measure of threshold was simply the stimulus amplitude resulting in a proportion of correct responses of .75 . Secondly, in our experiment, the menstrual cycle had an effect on the detection of vibration when vibration frequency was $250 \mathrm{~Hz}$ but not when it was $15 \mathrm{~Hz}$. Detection of stimuli of these two frequencies is known to be mediated by different populations of sensory receptors in the skin. If the effects of the menstrual cycle were cognitive-as would be changes in attention-or motivational-as would be changes in arousal-detecting $15-\mathrm{Hz}$ as well as $250-\mathrm{Hz}$ stimuli would be affected. Thus, although the mechanism is as yet unknown, it appears that some physiological change in Pacinian corpuscles and/or in parts of the central nervous system that process incoming information from Pacinian corpuscles is responsible for the effect of the menstrual cycle in the detection of vibration.

\section{EXPERIMENT 2}

The purpose of Experiment 2 was to examine the effects of the menstrual cycle on vibrotactile sensitivity for a period of several months. To this end, a single subject, tested for 11/2 months in Experiment 1, was tested for an additional 2 months in Experiment 2. By examining how the threshold changes over a period of 103 days, the reliability of the effects of the menstrual cycle on the detection of vibrotactile stimuli was assessed. It was also possible to identify both small and large variations in the threshold that were repeated at the same points in the cycle in successive months.

\section{Method}

Subject. The subject studied in this experiment was a 26-yearold woman, who was one of the seven subjects in Experiment 1. Her 250-Hz premenstrual and postmenstrual thresholds were substantially different.

Apparatus. The apparatus used in Experiment 2 was the same as that used in Experiment 1.

Procedure. The procedures used in Experiment 2 were the same as those used in Experiment 1, with the exception that testing was done on alternate days for a period of $31 / 2$ rather than $11 / 2$ months. Data reported in Experiment 2 for the first 42 days were the data obtained for this subject in Experiment 1 . It should also be noted that on six occasions during the 103-day testing period, sessions were either missed or had to be delayed by 1 day. Body weight was measured at each session, and skin temperature of the hand at the test site was monitored while the subject detected the test stimulus.

\section{Results and Discussion}

Thresholds for the detection of $15-\mathrm{Hz}$ and $250-\mathrm{Hz}$ stimuli are plotted as a function of days in Figure 4. Thresholds for the detection of $15-\mathrm{Hz}$ vibration varied irregularly as a function of days. The mean threshold was $4.57 \mathrm{~dB}$, and the standard deviation was $1.78 \mathrm{~dB}$. Thresholds for the detection of $250-\mathrm{Hz}$ vibration, on the other hand, varied systematically as a function of days. The mean threshold was $-27.63 \mathrm{~dB}$, and the standard deviation was $4.62 \mathrm{~dB}$. During each of the three menstrual cycles, thresholds were lower before than after the onset of the menstrual period (M) and were high for a day or two 12 to 14 days after the onset of the period. Thus, the sensitivity of the Pacinian, but not of the non-Pacinian, system of mechanoreception exhibits dramatic and reliable changes in sensitivity during the menstrual cycle. This system appears to be more sensitive just before than just after the onset of a menstrual period and in some cases may be least sensitive near the time of ovulation. 


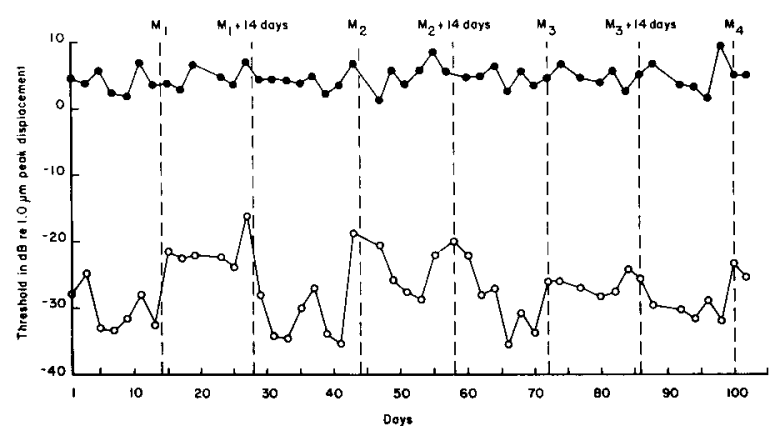

Figure 4. Absolute thresholds for the detection of 15- and 250-Hz stimuli as a function of days in three successive menstrual cycles of a single subject.

\section{EXPERIMENT 3}

Although the results of Experiments 1 and 2 indicate that vibrotactile sensitivity changes during the menstrual cycle, it was not determined whether hormone levels were correlated with psychophysical thresholds. To examine the role of hormones in vibrotactile sensitivity, four women taking birth control pills were tested every other day for 1 month, and the results were compared with those of the normally cycling women tested in Experiment 1. Birth control pills have the effect of maintaining high and relatively constant levels of estrogen and progesterone. It was thought that, if one or both of these hormones were responsible for the sensitivity changes observed in normally cycling women, women taking birth control pills should have relatively constant thresholds throughout their cycles. In addition, by comparing the thresholds of women taking birth control pills with those of normally cycling women, it should be possible to determine whether female hormones induce increases or decreases in vibrotactile sensitivity.

\section{Method}

Subjects. The subjects were four women, 19-22 years old, taking birth control pills consisting of moderate levels of progesterone $(1 \mathrm{mg})$ and estrogen $(.035-.050 \mathrm{mg})$. The subjects had started taking the pills several months prior to the experiment.

Apparatus. The apparatus was the same as that used in Experiments 1 and 2.

Procedure. The procedure was basically identical to that used in Experiment 1. Thresholds for the detection of $15-$ and $250-\mathrm{Hz}$ vibrotactile stimuli were measured every other day for a period of approximately 1 month.

\section{Results and Discussion}

Thresholds for the detection of 15 - and $250-\mathrm{Hz}$ stimuli are plotted as a function of days in Figure 5; threshold values for the 11 subjects of Experiment 1, shown in Figure 1, are repeated here for ease of comparison. Women taking birth control pills were slightly less sensitive than normally cycling women in detecting $15-\mathrm{Hz}$ stimuli and were substantially more sensitive than normally cycling women in detecting $250-\mathrm{Hz}$ stimuli. Varia- bility among subjects within each of the two groups was low. The standard error of the mean was calculated for each testing day in the cycle. The average standard error of the mean for detecting the $15-\mathrm{Hz}$ stimulus was $.86 \mathrm{~dB}$ (range .60-1.38 dB) and .95 dB (range .56-1.77 dB) for normally cycling subjects and subjects taking birth control pills, respectively. The average standard error of the mean for detecting the $250-\mathrm{Hz}$ stimulus was $1.65 \mathrm{~dB}$ (range 1.25-2.00 dB) and 1.66 dB (range .88-2.84 dB) for normally cycling subjects and subjects taking birth control pills, respectively. Two single-factor ANOVAs indicated that, for women taking birth control pills, thresholds for detecting $15-\mathrm{Hz}$ stimuli $[\mathrm{F}(13,39)=.31$, $\mathrm{p}>.05]$ and $250-\mathrm{Hz}$ stimuli $[\mathrm{F}(13,39)=.51, \mathrm{p}>.05]$ did not change significantly over the menstrual cycle. The thresholds of normally cycling women were as low as those of women taking birth control pills only on the testing session that took place 2 days before the onset of the menstrual period. Progesterone tends to be high in concentration a few days before the onset of menstruation. Thus, it may be progesterone, a hormone that is relatively high throughout the cycle of women taking birth control pills and high before menstruation in normally cycling women, that induces increased sensitivity in the Pacinian mechanoreceptive system. The physiological mechanism through which these sensitivity changes occur is not known, nor is the evolutionary significance of this phenomenon apparent.

\section{EXPERIMENT 4}

In Experiment 4, vibrotactile thresholds of a group of male subjects were compared with those of a group of normally cycling women and with a group of women taking birth control pills. Women were tested during the week before menstruation and during the week after menstrua-

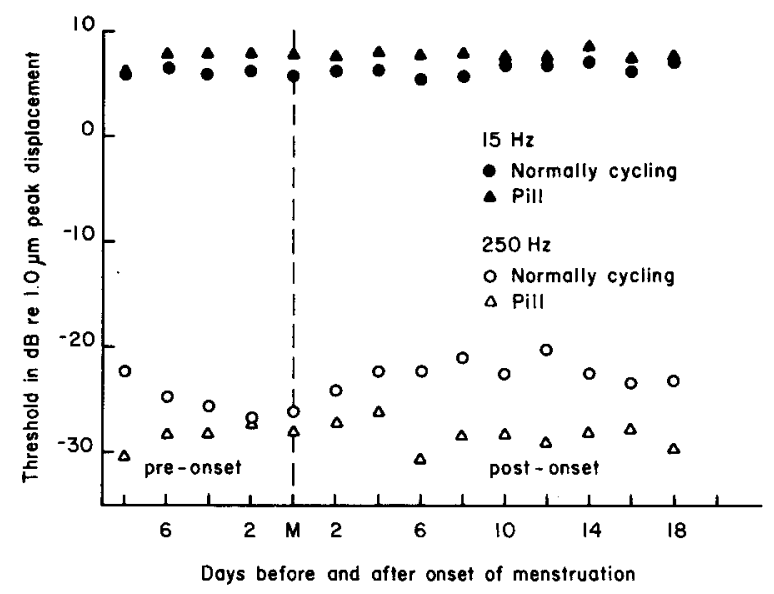

Figure 5. Absolute thresholds for the detection of 15- and 250-Hz stimuli as a function of days in the menstrual cycle. Circles represent the data of the 11 normally cycling subjects also shown in Figure 1, and triangles represent the data of four subjects who took birth control pills. 
tion. Men were tested on two occasions separated by 10 14 days. The experiment was a test of the hypothesis that high levels of female hormones produce high sensitivity in the Pacinian system, but have little effect on the sensitivity of the non-Pacinian system. According to this hypothesis, the thresholds for the detection of a $15-\mathrm{Hz}$ stimulus should not differ for normally cycling women and women taking birth control pills. Furthermore, women's $15-\mathrm{Hz}$ thresholds should be the same before and after menstruation, and these thresholds should not differ from male thresholds. On the other hand, $250-\mathrm{Hz}$ thresholds of normally cycling women should be lower before than after menstruation, whereas thresholds of women taking birth control pills should be relatively low after as well as before menstruation. Males were expected to have relatively high $250-\mathrm{Hz}$ thresholds, comparable to those measured in the postmenstrual period of normally cycling women.

\section{Method}

Subjects. The subjects were 24 normally cycling women, 11 women taking birth control pills, and 25 men. All female subjects had menstrual cycles with durations of $28 \pm 2$ days. The ages of the women ranged from 18 to 26 years. The ages of the male subjects ranged between 18 and 22 years.

Apparatus. The apparatus was the same as that used in Experiments 1,2 , and 3 .

Procedure. Thresholds for the detection of $15-$ and $250-\mathrm{Hz}$ stimuli were both measured in two sessions separated by approximately 10-14 days. For women, one session took place within the week prior to the onset of menstruation and the other occurred during the week following menstruation. On the basis of the results of the previous experiments on normally cycling women, the threshold for detecting a $250-\mathrm{Hz}$ stimulus should be lowest during the week prior to menstruation and highest during the week after. Approximately half of the subjects were tested before menstruation followed by a second testing after menstruation; the other subjects were first tested following menstruation and subsequently tested before menstruation.

\section{Results and Discussion}

The results are presented in Figure 6. The height of each bar indicates the mean threshold of each group of subjects for a particular stimulus frequency, and the vertical lines indicate the standard errors of the means. Statistical comparisons were made through $t$ tests. Consistent with the results of Experiments 1 and 2, the premenstrual and postmenstrual $15-\mathrm{Hz}$ thresholds of normally cycling women did not differ significantly, and, consistent with the results of Experiment 3, thresholds measured before and after menstruation did not differ in women taking birth control pills. The $15-\mathrm{Hz}$ thresholds of normally cycling women, women taking birth control pills, and men did not differ significantly. The results of this experiment indicate that levels of female hormones do not affect the sensitivity of the non-Pacinian system of mechanoreception.

On the other hand, the results strongly support the hypothesis that the sensitivity of the Pacinian system is affected substantially by changes in the level of female hormones. In normally cycling women, the mean 250 -

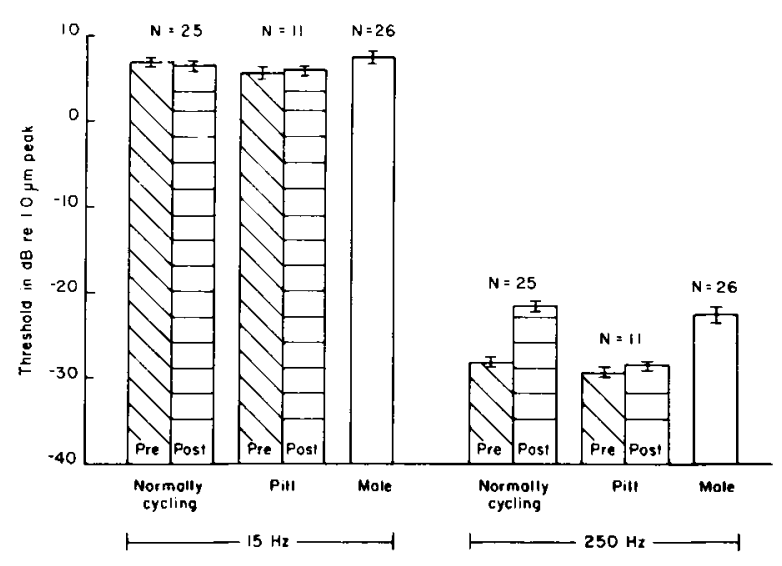

Figure 6. Absolute thresholds for the detection of $15-$ and $250-\mathrm{Hz}$ stimuli for men and for normally cycling women and women taking birth control pills tested before and after their menstrual periods.

$\mathrm{Hz}$ threshold was $-28.19 \mathrm{~dB}$ before menstruation and $-21.88 \mathrm{~dB}$ after menstruation. A t test revealed that these mean thresholds were significantly different $(p<.01)$. These results are in close agreement with those of $\mathrm{Ex}^{-}$ periments 1 and 2 , in which normally cycling women were found to be more sensitive to high-frequency vibration before than after menstruation. The mean premenstrual and postmenstrual $250-\mathrm{Hz}$ thresholds of women taking birth control pills did not differ significantly and were -29.32 and $-28.38 \mathrm{~dB}$, respectively. These thresholds, although significantly lower than the postmenstrual 250$\mathrm{Hz}$ thresholds of normally cycling women $(\mathrm{p}<.01)$, did not differ significantly from the premenstrual thresholds of these subjects. Presumably the same naturally produced hormones that induce premenstrual increases in sensitivity in normally cycling women induce increased sensitivity throughout the entire cycle in women receiving large amounts of these hormones through birth control pills. The mean of the male $250-\mathrm{Hz}$ thresholds of $-22.78 \mathrm{~dB}$ did not differ significantly from the mean postmenstrual threshold of $-21.88 \mathrm{~dB}$ of normally cycling women, but was significantly higher than the mean premenstrual threshold of $-28.19 \mathrm{~dB}$ of these women $(\mathrm{p}<.01)$ and the mean postmenstrual threshold of $-28.38 \mathrm{~dB}(\mathrm{p}<$ .01 ), as well as the mean premenstrual threshold of $-29.32 \mathrm{~dB}(\mathrm{p}<.01)$ of women taking birth control pills. One reason that male thresholds are so high may be the relative absence in these subjects of the female hormones that seem to induce increases in sensitivity to highfrequency vibration in normally cycling women and women taking birth control pills.

The finding that males and females differ in sensitivity to high-frequency vibration appears to be at odds with a report by Verrillo (1979), who found no sex difference in detection thresholds for vibration. In Verrillo's study, no attempt was made to test subjects at specific times of the menstrual cycle, and it may be that few, if any, of his subjects were tested during the premenstrual phase of the cycle when they would be most sensitive. It appears 
that women are no more sensitive than men in detecting vibration unless their psychophysical thresholds for detecting high-frequency vibration are measured a few days before the onset of menstruation, in which case their thresholds are, on the average, 6.0 or $7.0 \mathrm{~dB}$ lower than those of men.

The results of our experiments strongly suggest that the presence of one or both of the female hormones progesterone and estrogen has the effect of increasing the sensitivity of the Pacinian, but not of the non-Pacinian, mechanoreceptive system. In future research, the levels of these hormones will be measured each day and correlated with measurements of vibrotactile thresholds. From this research, the question of whether one or both hormones are involved may be answered.

\section{REFERENCES}

Barris, M. C., Dawson, W. W., \& Theiss, C. L. (1980). The visual sensitivity of women during the menstrual cycle. Documenta Ophthalmologica, 49, 293-301.

Bolanowski, S. J., JR., \& VerRillo, R. T. (1982). Temperature and criterion effects in the somatosensory system: A neurophysiological and psychophysical study. Journal of Neurophysiology, 48, 837-856.

GEsCHEIDER, G. A. (1976). Evidence in support of the duplex theory of mechanoreception. Sensory Processes, 1, 68-76.

Gescheider, G. A. (1985). Psychophysics: Method, theory and application. Hillsdale, NJ: Erlbaum.

Gescheider, G. A., Frisina, R. D., \& Verrillo, R. T. (1979). Selective adaptation of vibrotactile thresholds. Sensory processes, 3, 37-48.

Gescheider, G. A., O'MAlley, M. J., \& Verrillo, R. 'T. (1983). Vibrotactile forward masking: Evidence for channel independence. Journal of the Acoustical Society of America, 74, 474-485.

Gescheider, G. A., \& VerRILlo, R. T. (1982). Contralateral enhancement and suppression of vibrotactile sensation. Perception \& Psychophysics, 32, 69-74.

Gescheider, G. A., Verrillo, R. T., Capraro, A. J., \& Hamer, R. D. (1977). Enhancement of vibrotactile sensation magnitude and predictions from the duplex model of mechanoreception. Sensory Processes, 1, 187-203.

Gescheider, G. A., Verrillo, R. T., \& VAN Doren, C. L. (1982). Prediction of vibrotactile masking functions. Journal of the Acoustical Society of America, 72, 1421-1426.

Goolkasian, P. (1980). Cyclic changes in pain perception: An ROC analysis. Perception \& Psychophysics, 27, 499-504.

HAMER, R. D., VerRILlo, R. T., \& ZWISLOCKI, J. J. (1983). Vibrotactile masking of Pacinian and non-Pacinian channels. Joumal of the Acoustical Society of America, 73, 1293-1303.

Henkin, R. I. (1974). Sensory changes during the menstrual cycle. In M. Ferin, F. Halberg, R. M. Richart, \& R. L. van de Wiele (Eds.), Biorhythms and human reproduction. New York: Wiley.

HERREN, R. Y. (1933). The effect of high and low female sex hormone concentration on the two-point threshold of pain and touch and upon tactile sensitivity. Journal of Experimental Psychology, 16, 324-327.

Kenshalo, D. R. (1966). The cool threshold associated with phases of the menstrual cycle. Joumal of Applied Physiology, 21, 1031-1039.

Labs, S. M., Gescheider, G. A., FAY, R. R., \& LyONS, C. H. (1978). Psychophysical tuning curves in vibrotaction. Sensory Processes, 2 , 231-247.

Mair, R. G., Bouffard, J. A., ENGEN, T., \& MORTON, T. H. (1978). Olfactory sensitivity during the menstrual cycle. Sensory Processes, 2, 90-98.

Millodot, M., \& LAMONT, A. (1974). Influence of menstruation on corneal sensitivity. British Journal of Ophthalmology, 58, 752-756.

Mountcastle, V. B., LaMotte, R. H., \& CaRli, G. (1972). Detection thresholds for stimuli in humans and monkeys: Comparison with threshold events in mechanoreceptive afferent nerve fibers innervating the monkey hand. Journal of Neurophysiology, 35, 122-136.

PARLEe, M. B. (1983). Menstrual rhythms in sensory processes: A review of fluctuations in vision, olfaction, audition, taste, and touch. Psychological Bulletin, 93, 539-548.

RoBinson, J. E., \& SHORT, R. V. (1977). Changes in breast sensitivity at puberty, during the menstrual cycle, and at parturition. British Medical Journal, 1, 1188-1191.

Scher, D., Pionk, M., \& Purcell, D. G. (1981). Visual sensitivity fluctuations during the menstrual cycle under dark and light adaptation. Bulletin of the Psychonomic Society, 18, 159-160.

Talbot, W. H., Darian-Smith, I., Kornhuber, H. H., \& MountCASTLE, V. B. (1968). The sense of flutter-vibration: Comparison of the human capacity with response patterns of mechanoreceptive afferents from the monkey hand. Journal of Neurophysiology, 31, 301-334.

VERRILLO, R. T. (1963). Effect of contactor area on the vibrotactile threshold. Journal of the Acoustical Society of America, 35, 1962-1966.

VERRILLO, R. T. (1966a). Vibrotactile sensitivity and the frequencyy response of the Pacinian corpuscle. Psychonomic Science, 1966a, 4, 135-136.

VERRILLO, R. T. (1966b). Vibrotactile thresholds for hairy skin. Journal of Experimental Psychology, 72, 47-50.

VERRILLO, R. T. (1968). A duplex mechanism of mechanoreception. In D. R. Kenshalo (Ed.), The skin senses. Springfield, IL: Thomas.

VerRILLo, R. T. (1979). Comparison of vibrotactile threshold and suprathreshold responses in men and women. Perception \& Psychophysics, 26, 20-24.

Verrillo, R. T., \& Gescheider, G. A. (1975). Enhancement and summation in the perception of two successive vibrotactile stimuli. Perception \& Psychophysics, 18, 128-136.

Verrillo, R. T., \& Gescheider, G. A. (1977). Effects of prior stimulation on vibrotactile thresholds. Sensory Processes, 1, 292-300.

Verrillo, R. T., Gescheider, G. A., Calman, B. G., \& Van DoREN, C. L. (1983). Vibrotactile masking: Effects of one- and twosite stimulation. Perception \& Psychophysics, 33, 379-387.

Zwislocki, J. J., Maire, F., Feldman, A. S., \& Rubin, H. (1958). On the effect of practice and motivation on the threshold of audibility. Journal of the Acoustical Society of America, 30, 254-262.

(Manuscript received August 22, 1984; revision accepted for publication December 3, 1984.) 